\title{
Development a new method for pilot scale production of high grade oil palm plywood: effect of resin content on the mechanical properties, bonding quality and formaldehyde emission of palm plywood
}

\begin{abstract}
The main objectives of this research were to investigate the formaldehyde emission, some mechanical properties and bonding quality of oil palm trunk (OPT) plywood treated with low molecular weight phenolï formaldehyde (LmwPF), as affected by resin concentration. The mechanical properties are affected by different of amount resin solid contents used. The OPT veneer were treated at either $40 \%, 32 \%, 23 \%$ or $15 \%$ of resin concentration and $12 \mathrm{~mm}$ thickness of 3-ply plywood panel were manufactured for each group. In this study the formaldehyde emission, modulus of rupture (MOR), modulus of elasticity (MOE) and bonding quality (shear strength) of OPT plywood were determined. The results revealed that the resin-treatment method was tend to significantly improved the mechanical properties of the OPT plywood panel in which increased solid absorption gives better mechanical properties. Apparently, high mechanical properties were obtained for panel manufacturer from veneer treated with $32 \%$ and $40 \%$ resin content. The resin-treated OPT plywood provided superior mechanical strength with improvements at least 202\% MOE and 159\% MOR compared to commercial OPT plywood. Whereas, mechanical properties of the resintreated OPT plywood were drastically decrease with increasing the water substitution. Formaldehyde emission content of OPT panels decreased upon reduction of resin content into treatment process and were significant at resin concentration. The resin-treated OPT panels at $32 \%$ solid content provided a reasonable amount of free formaldehyde $(0.359 \mathrm{mg} / \mathrm{L})$ which attained F**** according to Japanese Agriculture Standard (JAS). The shear strength of resin-treated OPT plywood panel with $32 \%$ and $40 \%$ resin content achieved minimum requirements according to the standard European Norms EN 314-1 and EN 314-2 for the interior and exterior application.
\end{abstract}

Keyword: A. Natural materials; C. Surface treatments; E. Mechanical 